\title{
A Importância do Planejamento Financeiro para as Startups de Tecnologia da Informação da Região Metropolitana do Recife - PE
}

\author{
Valéria Silva $^{1,2}$, Ivaldir de Farias Junior ${ }^{1}$, Jeferson K. M. Vieira ${ }^{3}$ \\ ${ }^{1}$ Universidade de Pernambuco (UPE) \\ Pernambuco - PE - Brasil \\ ${ }^{2}$ Assespro PE/PB \\ ${ }^{3}$ Universidade Federal do Ceará (UFC) Campus Quixadá \\ Ceará - CE - Brasil \\ valeriana 2007@hotmail.com, ivaldir.fariaseupe.br, \\ jefersonkenedy.ufcegmail.com
}

\begin{abstract}
Resumo. $O$ objetivo desta pesquisa foi analisar a importância do planejamento financeiro para as startups de TI, que encontram-se instaladas ou associadas na Comunidade Manguez.AL, Assespro PE/PB e Softex Recife localizados na Região Metropolitana do Recife/PE. Para alcançar este objetivo, a pesquisa adotou como metodologia uma revisão informal da literatura juntamente com uma pesquisa de campo utilizando a abordagem qualitativa através de um questionário online. Como resultados, obtivemos as características do perfil deste tipo de empreendedor, as características do planejamento financeiro que está sendo adotado por estas startups e as dificuldades encontradas pelas para a sustentabilidade do negócio. A partir deste estudo, elaboramos um conjunto de práticas eficazes para auxiliar os startups na organização do seu planejamento financeiro.
\end{abstract}

Abstract. The objective of this research was to analyze the importance of financial planning for IT startups installed or associated in Comunidade Manguez.AL, Assespro PE/PB and Softex Recife located in the Metropolitan Region of Recife/PE. To achieve this objective, the research adopted as methodology an informal literature review together with a field research using the qualitative approach through an online questionnaire. As a result, we obtained the characteristics of the profile of this type of entrepreneur, the characteristics of the financial planning that is being adopted by these startups and the difficulties encountered by them for the sustainability of the business. From this study, we developed a set of effective practices to assist startups in organizing their financial planning.

\section{Introdução}

Startups são organizações pequenas que buscam conceber um modelo de negócio estável com o objetivo de escalar de forma exponencial o produto ou serviço a ser comercializado. Neste sentido, o aporte financeiro externo é algo crucial para operar 
(Paternoster et al., 2014). Quando falamos de startup, estamos afirmando que esse novo modelo de negócio tem como foco a criatividade e inovação contribuindo para o desenvolvimento econômico e tecnológico do país (Sutton, 2000). O ecossistema de Tecnologia da Informação (TI) é fomentado com a abertura de novas empresas, nomeadamente, startups (Paternoster et al., 2014; Giardino et al., 2016). Conforme um estudo realizado pela Fundação Dom Cabral (2015), com 130 startups em operação e 91 descontinuadas, sobre "As Causas da Mortalidade das startups Brasileiras", mostra que no Brasil, pelo menos $25 \%$ desses negócios morrem com um tempo inferior a 1 ano, $50 \%$ em menos de 4 anos e $75 \%$ em menos de 13 anos. Os aspectos apresentados que influenciaram na mortalidade dessas empresas foram: 1) o número de sócios envolvidos; 2) o volume de capital investido na startup anterior ao início das vendas; e 3) o local de instalação da empresa pode determinar as chances de sucesso.

\section{Metodologia}

Nesta pesquisa adotamos uma revisão informal da literatura de carater exploratório juntamente com a aplicação de uma survey (questionário online via Google Forms) com 55 startups da área de tecnologia. Com o objetivo de coletar os dados a serem analisados neste estudo, aplicamos um questionário com 19 questões abertas e fechadas (sendo 5 questões referente ao perfil do respondente e as demais com foco no perfil e planejamento financeiro). Esse questionário tinha como finalidade a obteção de informações sobre a visão dos empreendedores acerca da importância do planejamento financeiro para a sua startup de tecnologia (Ver Tabela I). A aplicação do questionário foi realizada de agosto a setembro de 2019. Foram convidadas 150 startups e obtivemos 55 respostas (taxa de resposta de 36,66\%). Vale salientar que somente um representante de cada startup resposndeu ao questionário.

Tabela I - Principais questões com foco no perfil e no planejamento financeiro das startups

\begin{tabular}{|l|}
\hline Perfil da Startup \\
\hline Classificação do tamanho da sua startup \\
\hline Qual é a idade da sua startup? \\
\hline A sua startup possui um planejamento financeiro? \\
\hline Qual é o prazo de aplicabilidade do planejamento financeiro da sua startup? \\
\hline Qual é o nível da importância do Planejamento Financeiro para a sustentabilidade do seu negócio? \\
\hline Quem é o responsável pelo Planejamento Financeiro da sua Startup? \\
\hline $\begin{array}{l}\text { Tipos de investimentos utilizados no negócio e práticas de melhorias adotadas para a } \\
\text { sustentabilidade financeira da startup }\end{array}$ \\
\hline \begin{tabular}{l} 
Qual o tipo de investimento que foi utilizado por sua startup na fase inicial do negócio? \\
\hline Em que fase da Startup foi necessário o aporte de capital de terceiros?
\end{tabular} \\
\hline $\begin{array}{l}\text { Quais os instrumentos financeiros que são utilizados para análise da viabilidade financeira e retorno do } \\
\text { investimento do seu negócio? }\end{array}$ \\
\hline $\begin{array}{l}\text { Que tipo de Assessoria Externa foi utilizada para o desenvolvimento do seu negócio nos primeiros anos } \\
\text { de criação? }\end{array}$ \\
\hline $\begin{array}{l}\text { O Ecossistema Tecnológico de Recife/PE tem contribuído para o desenvolvimento do seu negócio? Caso } \\
\text { sim, descreva de que forma é realizada esta contribuição? }\end{array}$ \\
\hline
\end{tabular}


Quais as melhores práticas financeiras adotadas por sua empresa, a fim de alavancar o crescimento e a sustentabilidade do seu negócio?

No cenário atual, quais foram as dificuldades encontradas por sua empresa para manter-se ativa no mercado, desde o início das atividades?

Qual é a importância do planejamento financeiro para a sua startup? Por quê?

\section{Resultados}

\subsection{Características dos tipos de investimentos utilizados no negócio e práticas financeiras eficazes para a sustentabilidade da Startup}

No que tange ao uso de Capital de Terceiros, 52.7\% dos respondentes informaram que não utilizaram o aporte desse capital na sua empresa. Outros $20 \%$ usaram na fase de crescimento da startup, $16.4 \%$ na fase de nascimento e validação, $7.3 \%$ na fase de gestação e, apenas $3.6 \%$ usaram na fase de concepção da ideia, ou seja, fase inicial. Acerca dos Instrumentos Financeiros utilizados pelas Startups percebe-se que os maiores percentuais de respostas estão distribuídos em: Fluxo de Caixa (detalhado mensalmente) (60\%), Demonstrativo de Resultados (56.4\%), Planilhas Financeiras Eletrônicas (52.7\%), Indicadores Financeiros (41.8\%) e Demonstrativo de Fluxo de Caixa (38.2\%). Já os que utilizam um Sistema Integrado de Gestão Empresarial correspondem a $20 \%$. Os menores percentuais estão distribuídos em: Balanço Patrimonial (14,5\%), usuário do Conta Azul e de Sistema Próprio corresponde a $1,8 \%$. Vale destacar que $10,9 \%$ dos gestores não utilizam nenhum tipo de instrumento financeiro no seu negócio.

\subsection{Análise dos principais desafios encontrados pelas Startups Pernambucanas}

Acerca dos desafios elencados pelas empresas participantes, destacaram-se: a falta de caixa para investir e a falta de clientes/vendas (13 startups); atrair e reter talentos/turnover/mão de obra especializada (8 startups); desafios com marketing e vendas ( 8 startups); barreiras de entradas no mercado ( 5 startups); falta de investimento de terceiros (5 startups); novos desafios tecnológicos (4 startups); concorrência (3 startups); definição e validação de um modelo de negócio sustentável e escalável (2 startups); falta de legislação (2 startups); e, apenas 1 startup, apresentou a inadimplência como dificuldade.

\subsection{Análise sobre a importância do planejamento financeiro para Startups}

Analisando as respostas dos empreendedores quando são questionados sobre a importância do planejamento financeiro para a sua startup, extraímos os seguintes resultados: $85.45 \%$ dos respondentes consideram muito importante ter um planejamento financeiro; $1.8 \%$ consideram de importância intermediária; $3.6 \%$ consideram pouco importante; $1.8 \%$ dos respondentes não souberam informar; e $5.5 \%$ dos respondentes não possuem planejamento financeiro.

\section{Práticas Eficazes para a Sustentabilidade Financeira das Startups}

Essas práticas que foram extraídas da pesquisa com as 55 startups, têm por objetivo auxiliar os empreendedores a organizarem o planejamento financeiro do seu negócio de forma assertiva, pois essas empresas possuem um crescimento escalável em curto prazo e precisam gerar um bom fluxo de caixa para sustentar o negócio no estágio 
inicial das atividades. Vale salientear que essas 10 práticas descritas nesta seção, foram as que mais foram citadas pelos representantes das startups participantes da pesquisa. A seguir, descrevemos o conjunto das boas práticas sugeridas, com as suas respectivas legendas (exemplo: $\mathrm{P} 1=$ prática $1, \mathrm{P} 2$ = prática 2 , e assim por diante):

- Controlar, Gerir e Acompanhar o Fluxo de Caixa Detalhado (P1): para funcionar é preciso controlar o fluxo de caixa com a finalidade de analisar as entradas e saídas dos recursos financeiros da empresa, com uma frequência mensal, semanal ou diária. De acordo com Chiavenato (2012), o fluxo de caixa - constitui o termômetro do dia a dia da empresa, ou seja, mostra o comportamento dela quanto aos recebimentos e aos pagamentos de suas operações.

- Controlar os Custos e as Despesas (P2): visa controlar os custos e as despesas da startup, rigorosamente, com o objetivo de reduzir gastos desnecessários e garantir recursos para manter os pagamentos em dia. A Endeavor (2019), ressalta que o controle de gastos é essencial para fornecer as informações necessárias sobre a rentabilidade e desempenho das atividades da empresa. Além disso, essa gestão auxilia o planejamento, controle e desenvolvimento das diversas operações da empresa.

- Utilizar Sistemas de Controle de Finanças, Software, ERP e Planilhas Eletrônicas Financeiras (P3): visa dar mais atenção a implantação de sistemas de controle de finanças, software, ERP para viabilizar e automatizar as operações financeiras do negócio, através destes sistemas a empresa terá fácil acesso à emissão de relatórios e informações relevantes para a tomada de decisão.

- Focar em vendas, Receitas Recorrentes e Margem de Lucro Líquido (P4): destaca que o gestor deve focar em estabelecer metas e estratégias de vendas a fim de aumentar as entradas de receitas e, consequentemente, aumentar a sua margem de lucro líquido.

- Analisar os Indicadores Financeiros (P5): busca analisar todos os indicadores financeiros da empresa e relacioná-los com outros instrumentos financeiros, tais como: DRE, Fluxo de Caixa, Balanço Patrimonial, dentre outros, a fim de obter uma análise completa da situação econômico-financeira da startup.

- Analisar os Demonstrativos Contábeis e Financeiros (P6): Balanço Patrimonial (BP), Demonstração de Resultados do Exercício (DRE) e Demonstração do Fluxo de Caixa (DFC), promove a analise dos demonstrativos contábeis-financeiros frequentemente a fim de mapear a situação econômico-financeira do negócio.

- Dispor de Capital de Giro - CDG (P7): busca manter e acompanhar sempre o nível de capital de giro disponível para o negócio. Para Matos (2017), levantar capital é uma atividade muito importante para qualquer empresa, e existem diversas formas de fazer isso - além de receber investimentos de capital de risco já tradicionais no mundo das startups.

- Controlar rigorosamente o Orçamento de Gastos (P8): estabelece o controle rigoroso do orçamento de gastos. O foco é gastar menos do que o faturamento da empresa. 
- Elaborar o Planejamento Financeiro da Empresa (P9): visa elaborar o planejamento financeiro da startup, tendo em vista, o seu modelo de negócio e alinhá-lo ao planejamento estratégico.

- Construir uma Projeção Financeira e de Resultados (P10): elaborar uma projeção de receitas e despesas para o negócio através de ferramentas financeiras, prevendo e controlando o que foi projetado para curto e médio prazo. Projeções financeiras são extremamente importantes para que empreendedores gerenciem suas empresas: elas são ferramentas de gestão, não só algo a ser apresentado a investidores (Endeavor, 2019).

Vale salientar, que as práticas citadas são recomendações para auxiliar as startups a serem efetivos no planejamentofinanceiro da empresa denominada startup.

\section{Considerações Finais}

Através deste estudo, elaboramos um conjunto de boas práticas financeiras que poderão auxiliar os atuais e futuros empreendedores, principalmente de startups em seu planejamento financeiro, além de auxiliar no alavacamento e do crescimento sustentável do negócio. Por fim, concluímos que apesar do estudo ter sido aplicado a um número significativo de startups do ecossistema tecnológico da cidade do Recife, tivemos a limitação de não acompanhar/obsevar na prática o planejamento financeiro das startups, bem como a não aplicação das práticas em um cenário real. Sugerimos como trabalhos futuros, a aplicação das práticas do planejamento financeiro em um ambiente real, ou seja, em startups, seja de Pernambuco ou de outras regiões do Brasil buscando aplicar uma abordadegm quali-quanti.

\section{References}

N. Paternoster, C. Giardino, M. Unterkalmsteiner, T. Gorschek, and P. Abrahamsson, "Software development in startup companies: A systematic mapping study," Information and Software Technology, vol. 56, no. 10, pp. 1200-1218, 2014.

S. M. Sutton, “The role of process in software start-up,” IEEE Software, vol. 17, no. 4, pp. 33$39,2000$.

Fundação Dom Cabral. Causa da mortalidade das startups brasileiras: como aumentar as chances de sobrevivência no mercado, 2015. Disponível em: $<$ https://www.fdc.org.br/conhecimento/publicacoes/artigo-29767>. Acesso em: 29 jul. 2019.

C. Giardino, N. Paternoster, M. Unterkalmsteiner, T. Gorschek, and P. Abrahamsson, "Software development in startup companies: the greenfield startup model," IEEE Transactions on Software Engineering, vol. 42, no. 6, pp. 585-604, 2016.

Endeavor Brasil. Planejamento financeiro: um passo a passo indispensável, 2015. Disponível em: <https://endeavor.org.br/financas/planejamento-financeiro/>. Acesso em 23 jun. 2019.

I. Chiavenato. Empreendedorismo: dando asas ao empreendedor. 4. ed. São Paulo: Manole, 2012.

F. Matos. 10 mil startups: guia prático para começar a crescer o seu negócio digital no Brasil. 1. ed. São Paulo: Mariposa, 2017. 